\title{
CdTe Quantum Dots Embedded in Multidentate Biopolymer Based on Salep: Characterization and Optical Properties
}

\author{
Ghasem Rezanejade Bardajee and Zari Hooshyar \\ Department of Chemistry, Payame Noor University, P.O. Box 19395-3697, Tehran, Iran \\ Correspondence should be addressed to Ghasem Rezanejade Bardajee; grezanejad@ymail.com
}

Received 30 April 2013; Revised 28 June 2013; Accepted 28 June 2013

Academic Editor: Fa-Nian Shi

Copyright (c) 2013 G. Rezanejade Bardajee and Z. Hooshyar. This is an open access article distributed under the Creative Commons Attribution License, which permits unrestricted use, distribution, and reproduction in any medium, provided the original work is properly cited.

\begin{abstract}
This paper describes a novel method for surface modification of water soluble CdTe quantum dots (QDs) by using poly(acrylic acid) grafted onto salep (salep-g-PAA) as a biopolymer. As-prepared CdTe-salep-g-PAA QDs were characterized by Fourier transform infrared (FT-IR) spectrum, thermogravimetric (TG) analysis, and transmission electron microscopy (TEM). The absorption and fluorescence emission spectra were measured to investigate the effect of salep-g-PAA biopolymer on the optical properties of CdTe QDs. The results showed that the optical properties of CdTe QDs were significantly enhanced by using salep-g-PAA-based biopolymer.
\end{abstract}

\section{Introduction}

CdTe quantum dots (QDs) are novel high-efficiency fluorescence materials with unique chemical and physical properties [1-3]. They have been increasingly utilized in several technological areas such as solar photovoltaic cells, nanobarcodes, field effect transistors, light emitting diodes, photocatalysis, in vivo biomedical detection fluorescent tags in biology, and chemical and biological sensors [4-9]. In a general way, there are two ways to make CdTe QDs with desired optical properties, organometallic and aqueous syntheses [10, 11]. Compared with the organic synthesis, aqueous methods for QDs preparation are reasonably simple, economical, and environmentally friendly [12-14].

Water-soluble CdTe QDs can be synthesized through the selection of appropriate ligand molecules such as thioglycolic acid (TGA) and 3-mercaptopropionic acid, but low quantum yields (QYs) are typically obtained [15-17]. To remove these defects, surface modification of these water soluble CdTe QDs by polysaccharides is a suitable strategy [18-20]. Polysaccharides are the most viable, because the biopolymers are basically obtained from natural sources and are biodegradable. Salep is a nontoxic and stable water-soluble polysaccharide extracted from dried tubers of certain natural terrestrial orchids possessing interesting gelling properties widely explored for a variety of life science applications. It is a biopolymer composed of a linear copolymer which consists of glucomannan (16-60\%), starch $(2.7 \%)$, nitrogenous substance $(5 \%)$, moisture (12\%), and ash (2.4\%) [2123]. Therefore, it is a good source of glucomannan which contains natural, neutral, and water-soluble fibers and can assist to normalize blood sugar, relieve stress on the pancreas, and discourage blood. In this paper, we present a novel strategy for surface modification of CdTe QDs by poly(acrylic acid) grafted onto salep (salep-g-PAA) (Scheme 1). This new synthesis procedure was carried out in aqueous phase at low temperature conditions and can be a good candidate for wide applications in biological detection.

\section{Experimental}

2.1. Materials. Salep $\left(M_{n}=1.17 \times 10^{6} \mathrm{~g} / \mathrm{mol}, M_{w}=1.64 \times\right.$ $10^{6} \mathrm{~g} / \mathrm{mol}\left(\right.$ high $\left.M_{w}\right), \mathrm{PDI}=1.39$, eluent $=$ water, flow rate $=$ $1 \mathrm{~mL} / \mathrm{min}$, and acquisition interval $=0.43 \mathrm{~s}$ from GPC results) was purchased from a supplier in Kurdistan, Iran. Acrylic acid (AA) (98\%), thioglycolic acid (TGA, 98\%), $\mathrm{CdCl}_{2} \cdot 5 \mathrm{H}_{2} \mathrm{O}$ (99.99\%), tellurium (Te) powder (99.997\%), and sodium borohydride $\left(\mathrm{NaBH}_{4}, 95 \%\right)$ were purchased from SigmaAldrich. Ammonium persulfate (APS, 99\%) was obtained 


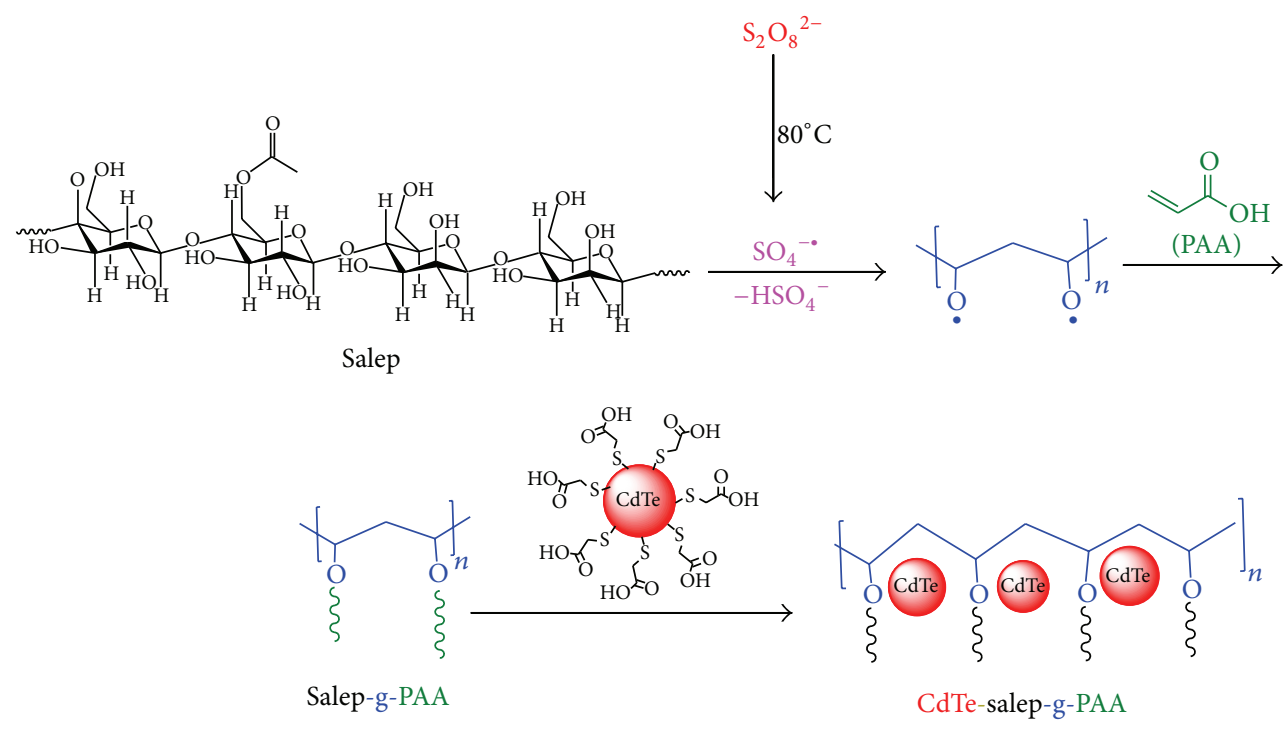

Scheme 1: Schematic illustration for the preparation of CdTe- salep-g-PAA QDs.

from Fluka and was used without further purification. All other chemicals and solvents were of analytical-reagent grade from LOBA chemicals (India). Double distilled water was used to prepare all the solutions.

2.2. Characterization Techniques. UV-vis absorption and fluorescence spectra of the samples were recorded with a Shimadzu UV-visible 1650 PC spectrophotometer and a SCINCO's fluorescence spectrometer fluoroMate FS-2, respectively. Thermogravimetric (TG) analysis of the samples was carried out with a TA Instruments model SDT Q600 under a dynamic $\mathrm{N}_{2}$ atmosphere from 35 to $600^{\circ} \mathrm{C}$ at a constant heating rate of $10^{\circ} \mathrm{C} / \mathrm{min}$. Transmission electron microscopy (TEM) was performed using a Hitachi $\mathrm{H}-700$ CTEM. FT-IR spectra of samples in the form of $\mathrm{KBr}$ pellets were recorded using a Jasco 4200 FT-IR spectrophotometer.

2.3. Synthesis of CdTe-TGA QDs. CdTe-TGA QDs were prepared according to the method described previously [15]. Briefly, under $\mathrm{N}_{2}$ atmosphere, deionized water $(2.5 \mathrm{~mL})$ was added to Te powder $(0.025 \mathrm{~g})$ and $0.025 \mathrm{~g}$ of $\mathrm{NaBH}_{4}$ under magnetic stirring at room temperature. After about $2 \mathrm{~h}$, the colorless solution of NaHTe was prepared. Then, NaHTe was added to cadmium chloride solution in the presence of TGA under $\mathrm{N}_{2}$ atmosphere with a molar ratio of $\mathrm{Cd}^{2+}: \mathrm{Te}^{2-}$ : TGA fixed at $1: 0.5: 2.4$. After mixing, the solution was heated to $100^{\circ} \mathrm{C}$ for $1 \mathrm{~h}$, and then CdTe-TGA QDs could be obtained.

2.4. Preparation of CdTe-Salep-g-PAA QDs. The synthesis of salep-g-PAA was as follows: AA $(4 \mathrm{~mL}, 5.8 \mathrm{mmol})$ was added to a three-neck reactor which contained homogenized mixture of salep $(1.0 \mathrm{~g})$ in water $(80 \mathrm{~mL})$. APS $(0.09 \mathrm{~g}$ $(0.4 \mathrm{mmol}))$ in double distilled water $(5.0 \mathrm{~mL})$ was slightly added to the previous solution, while temperature of reactor was controlled by a thermostated water bath at $80^{\circ} \mathrm{C}$. After 30 min stirring, the formed viscous solution was dewatered by ethanol $(200 \mathrm{~mL})$ to remove unreacted monomers and homopolymers. The synthesized CdTe-TGA QDs were added to the viscous solution of salep-g-PAA (CdTe-TGA/salep-g$\mathrm{PAA}=1: 4)$ (Scheme 1). The solution was stirred for $60 \mathrm{~min}$ at room temperature to ensure distribution of the CdTe QDs into the biopolymer matrix. Meanwhile, the optical properties of the solution were studied via UV-visible absorption and fluorescence measurements at $25^{\circ} \mathrm{C}$. After that, the ethanol was added to the solution and centrifuged, and the residue was collected for further experiments.

\section{Results and Discussion}

To obtain the optimized reaction conditions, we initially changed various reaction parameters including precursor ratios, $\mathrm{pH}$ values, and refluxing times to find their optimum values respecting to higher emission intensity of the resultant CdTe-TGA QDs. For example, changing the refluxing time showed that the $1 \mathrm{~h}$ heating time has the best efficiency. In this regard, to a three-neck round bottom flask containing deionized water $(2.5 \mathrm{~mL})$, Te powder $(0.025 \mathrm{~g})$ was added under $\mathrm{N}_{2}$ atmosphere. Then, the flask was charged with $0.025 \mathrm{~g}$ of $\mathrm{NaBH}_{4}$ under magnetic stirring at room temperature. After about $2 \mathrm{~h}$, the colorless solution of NaHTe was prepared. The NaHTe solution was added to cadmium chloride solution (from dissolving $0.11 \mathrm{~g} \mathrm{CdCl}_{2}$ in $80 \mathrm{~mL}$ deionized water) in the presence of TGA at $\mathrm{pH}=8$ and under $\mathrm{N}_{2}$ atmosphere with a molar ratio of $\mathrm{Cd}^{2+}$ : $\mathrm{Te}^{2-}$ : TGA fixed at $1: 0.5: 2.4$. After mixing, the solution was heated to $100^{\circ} \mathrm{C}$ for $1 \mathrm{~h}$, and then CdTe-TGA QDs could be obtained. Figure 1(a) shows the UV-vis absorption spectra of salep-gPAA, CdTe-TGA, and CdTe-salep-g-PAA QDs. The salep-gPAA showed little absorption. The CdTe-salep-g-PAA QDs exhibit a small shoulder around $460 \mathrm{~nm}$ which corresponds to the exciting transition from the highest occupied molecular orbital (HOMO) in the valence band to the lowest unoccupied molecular orbital (LUMO) in the conduction band $[24,25]$. To more investigation, band gap energy of 


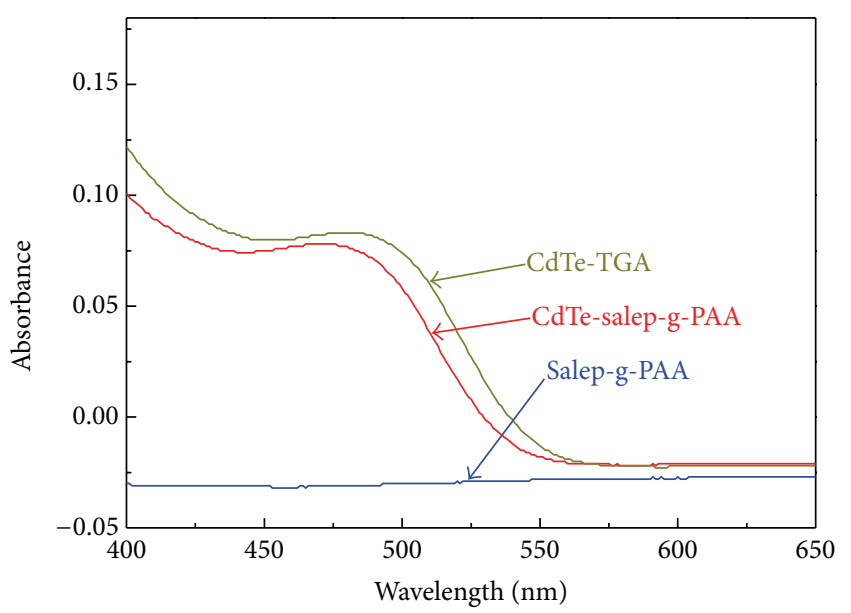

(a)

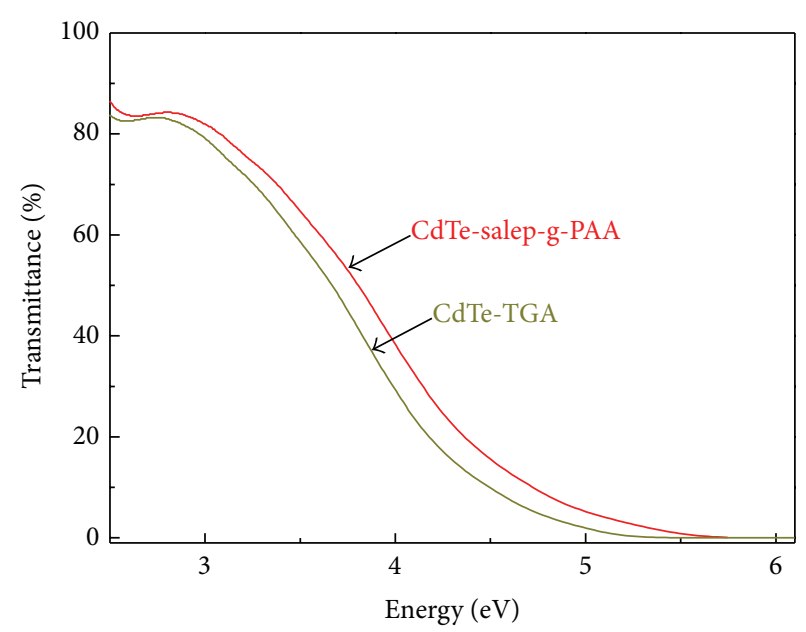

(b)

FIGURE 1: (a) UV-vis absorption and (b) transmittance spectrum of salep-g-PAA, CdTe-TGA, and CdTe-salep-g-PAA QDs.

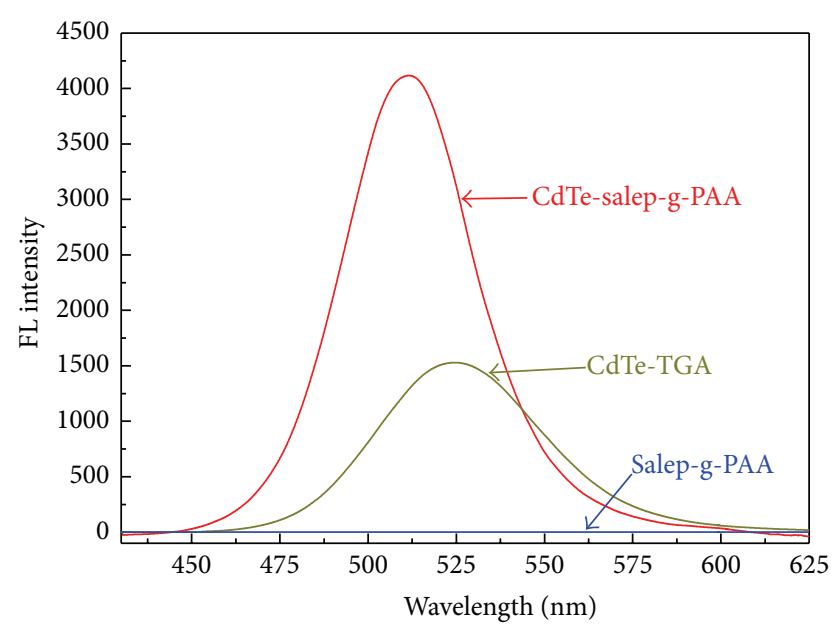

Figure 2: Fluorescence spectra of salep-g-PAA, CdTe-TGA, and CdTe-salep-g-PAA QDs $\left(\lambda_{\mathrm{ex}}\right.$ for emission spectra $\left.=380 \mathrm{~nm}\right)$.

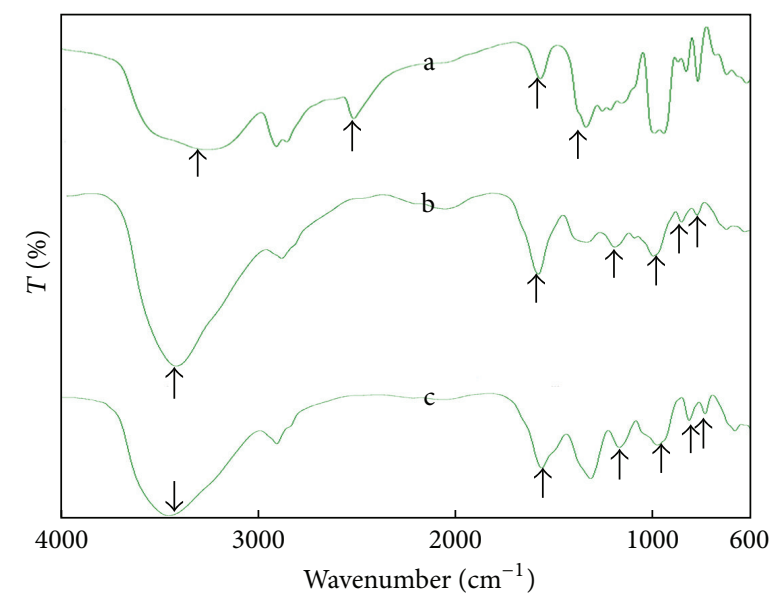

FIgURE 3: FT-IR spectra of (a) CdTe-TGA QDs, (b) salep-g-PAA, and (c) CdTe- salep-g-PAA QDs.

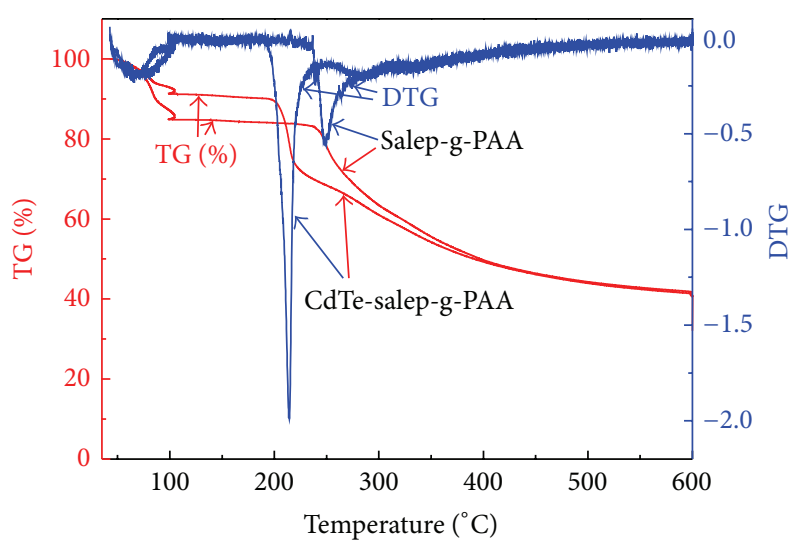

Figure 4: TG/DTG curves of CdTe-salep-g-PAA and salep-g-PAA.

CdTe-TGA and CdTe-salep-g-PAA QDs was calculated from the middle of shoulder in transmittance spectra as they are shown in Figure 1(b). The observed band gap of CdTe-salepg-PAA QDs is $1.77 \mathrm{eV}$, which is bigger than the band gap value of $1.56 \mathrm{eV}$ for CdTe-TGA QDs. This indicates that the CdTe-salep-g-PAA QDs display an obvious blue shift compared with the CdTe-TGA QDs, which may be attributed to the smaller size of CdTe QDs into salep-g-PAA biopolymer matrix. Brus has developed a popular effective mass model that relates particle size (neglecting spatial correlation effects) to the band gap energy of a semiconductor quantum dot [26]:

$$
\begin{aligned}
E_{g}(\mathrm{QDs})= & E_{g}(\text { bulk })+\left(\frac{h^{2}}{8 R^{2}}\right) \\
& \times\left(\frac{1}{m_{e}}+\frac{1}{m_{h}}\right)-\frac{1.8 e^{2}}{4 \pi \varepsilon_{0} \varepsilon R},
\end{aligned}
$$

where $E_{g}$ is the band gap energy of the quantum dot or bulk solid, $R$ is the quantum dot radius, $m_{e}$ is the effective mass of the electron in the solid, $m_{h}$ is the effective mass of the hole in the solid, and $e$ is the dielectric constant of the solid. 


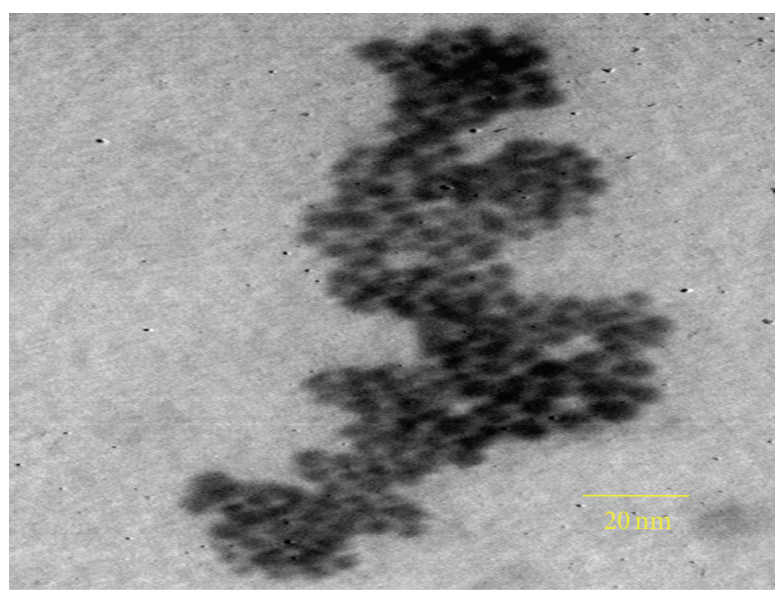

(a)

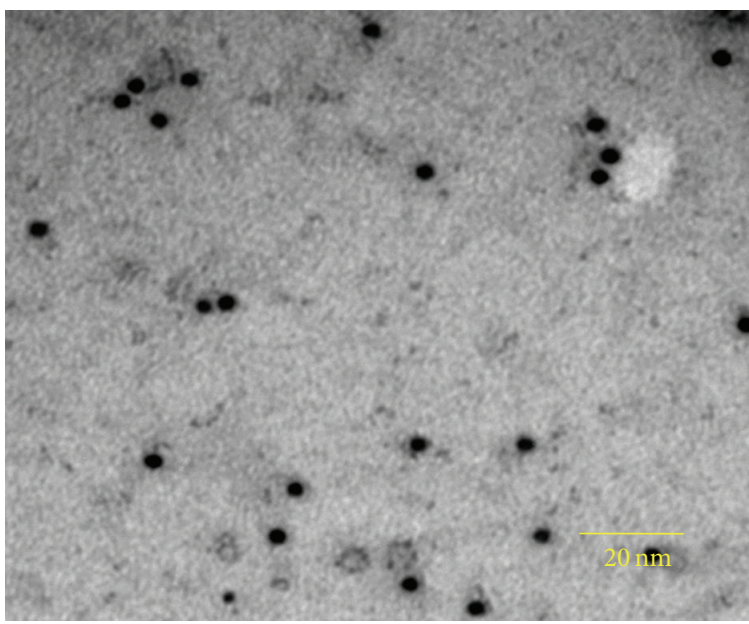

(c)

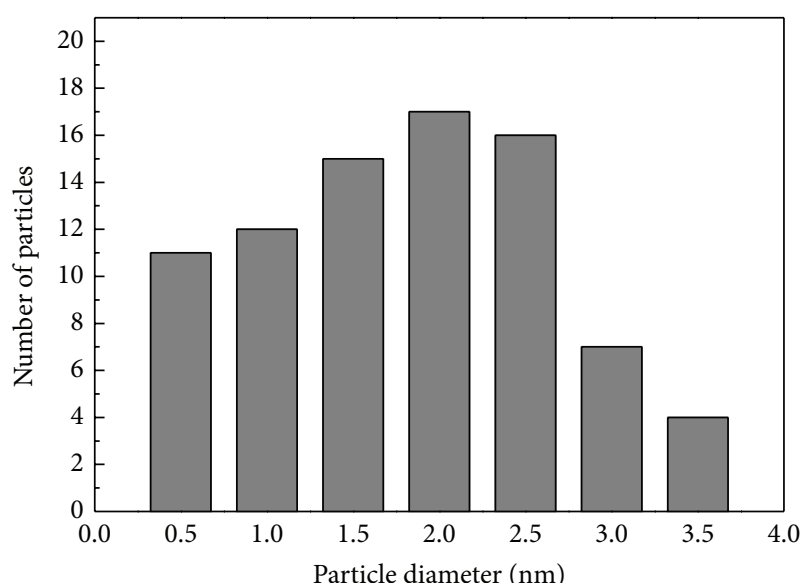

(b)

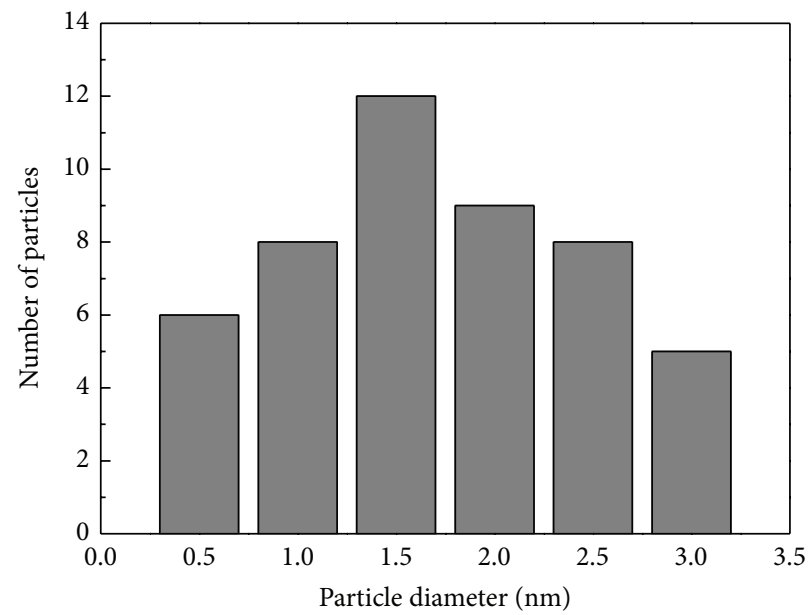

(d)

FIgure 5: TEM images and the particle size histograms of the (a) and (b) CdTe-TGA QDs and (c) and (d) CdTe-salep-g-PAA QDs.

By taking (1), the average particle diameter of CdTe-TGA and CdTe-salep-g-PAA QDs are estimated as 1.78 and $1.43 \mathrm{~nm}$, respectively.

Figure 2 shows the fluorescence spectra of salep-gPAA, CdTe-TGA, and CdTe-salep-g-PAA QDs. The excitation wavelength was $380 \mathrm{~nm}$. No fluorescence phenomenon was observed in salep-g-PAA for wavelength ranging from $430 \mathrm{~nm}$ to $625 \mathrm{~nm}$. Comparing to the CdTe-TGA, the fluorescence intensity of CdTe-salep-g-PAA QDs increased and the emission peak $(525 \mathrm{~nm})$ was blue shifted $(10 \mathrm{~nm})$. The QY of the prepared QDs was determined by the comparative method, in which rhodamine $6 \mathrm{G}$ was used as a reference standard $(\mathrm{QY}=0.90)$. The absorbance and the integrated fluorescence intensities of five samples of rhodamine $6 \mathrm{G}$ and QDs were measured. The slopes of the plot of the absorbance against the integrated fluorescence intensities in water were obtained and used to calculate the QY according to the following equation:

$$
\Phi_{X}=\Phi_{\mathrm{ST}}\left(\frac{S_{X}}{S_{\mathrm{ST}}}\right)\left(\frac{n_{X}}{n_{\mathrm{ST}}}\right)^{2}
$$

where ST and $X$ denote standard (rhodamine $6 \mathrm{G}$ ) and test samples, respectively and $S$ is the slope of the line obtained from the plot of the integrated fluorescence intensity versus absorbance. $\Phi$ is QY and $n$ is the refractive index of solvent. The QY of CdTe-salep-g-PAA QDs was 0.39, which was more than the QY of CdTe-TGA QDs (0.29). This is because the salep-g-PAA biopolymer suppressed deep trap emissions by passivating most of the vacancies and trapping sites on the CdTe QDs surface and resulted in fluorescence dominated by band edge recombination.

FT-IR spectra of CdTe-TGA QDs, salep-g-PAA, and CdTe-salep-g-PAA QDs are given in Figure 3. In the spectrum of CdTe-TGA QDs (curve (a)), peaks at 3400, 2600, 1633 , and $1461 \mathrm{~cm}^{-1}$ represent $\mathrm{O}-\mathrm{H}$ vibration of the absorbed $\mathrm{H}_{2} \mathrm{O}$, thiols stretching vibrations, carbonyl stretching vibration, and methylene scissoring vibration of mercaptoacetic acid coated on the surface of QDs. Peaks in the spectrum of salep-g-PAA (curve (b)) at 3400, 1630,1420, and $1250 \mathrm{~cm}^{-1}$ correspond to the stretching of hydroxyl and carboxylic acid groups, carbonyl groups of carboxylic acid moieties, symmetrical and asymmetrical stretching of ester groups in glucomannan of salep, respectively. As expected, in the case 
of the CdTe salep-g-PAA QDs (curve (c)), the characteristic peaks of CdTe-TGA QDs disappear, and the shape of the spectra is similar to curve (b). However, in the spectrum of CdTe-salep-g-PAA QDs, a little shift in some signals can be attributed to the chelating of the biopolymer functional groups on the surface of QDs.

Figure 4 shows the TG and DTG curves of salep-g-PAA and CdTe-salep-g-PAA in the temperature range from 35 to $600^{\circ} \mathrm{C}$. Weight losses of salep-g-PAA occur at two different temperatures ranges. The first stage occurs from 35 to $95^{\circ} \mathrm{C}$ with a weight loss of $17 \%$. The second stage starts from $248^{\circ} \mathrm{C}$ with a loss of $57 \%$. For DTG curve of salep-g-PAA, the peak at $63^{\circ} \mathrm{C}$ in the first range ( 35 to $95^{\circ} \mathrm{C}$ ) is resulted from the loss of water molecules adsorbed on salep-g-PAA; whereas, the peak at $248^{\circ} \mathrm{C}$ in the second range $\left(248-450^{\circ} \mathrm{C}\right)$ corresponds to the degradation of salep-g-PAA biopolymer. Compared with the TG curve of salep-g-PAA, there are two obvious alterations in the TG of CdTe-salep-g-PAA. First, desorption of water adsorbed in CdTe-salep-g-PAA QDs is shifted to lower temperature with the introduction of CdTe QDs. There are intermolecular and intramolecular hydrogen bonding which existed in the salep-g-PAA. However, this hydrogen bonding may be broken due to the chelation between CdTe and salep-g-PAA in solution, leading to the much weaker action between CdTe-salep-g-PAA and water molecules adsorbed in the obtained QDs. On the other hand, the residual weights for raw salep-g-PAA and CdTe-salep-g-PAA QDs are 41 and 43 wt.\%, respectively. Obviously, excess residual components for CdTe-salep-g-PAA indicate that CdTe QDs have been embedded in salep-g-PAA biopolymer.

Figure 5 provides the TEM images and size distributions of the CdTe-TGA QDs and CdTe-salep-g-PAA QDs. As shown in Figure 5, the TEM images illustrate the nearly spherical and monodispersed CdTe QDs into salep-g-PAA biopolymer matrix. The diameters of the QDs are estimated to be $2 \mathrm{~nm}$ for the CdTe-TGA QDs and $1.5 \mathrm{~nm}$ for CdTesalep-g-PAA QDs which are in good agreement with the results obtained from the absorption spectra. Besides, the small size of the CdTe-salep-g-PAA QDs would facilitate their penetration in biosystems when they have been used as fluorescent biological probes and we will report the in vitro cytotoxicity of CdTe-salep-g-PAA QDs in the near future.

The XRD spectra of the CdTe-TGA and CdTe- salep-gPAA QDs are shown in Figure 6. As it is shown in Figure 6, there are broad peaks at $2 \theta$ values of $23.8^{\circ}, 40.3^{\circ}$, and $46.9^{\circ}$, corresponding to the crystal planes (lll 111$),\left(\begin{array}{lll}2 & 2 & 0\end{array}\right)$, and (3 11 1) of zinc blend structure of CdTe QDs, and it is consistent with pure CdTe (JCPDS No. 15-0770) [27, 28]. To estimate the average diameter of the CdTe-TGA and CdTesalep-g-PAA QDs by Scherrer's formula, the main XRD peaks $\left(\begin{array}{lll}1 & 1 & 1\end{array}\right)$ were used. The average particle sizes of CdTe-TGA and CdTe- salep-g-PAA QDs were calculated to be 1.76 and $1.45 \mathrm{~nm}$, respectively.

\section{Conclusion}

In summary, fluorescent CdTe QDs capped by salep-g-PAA biopolymer were synthesized in aqueous medium at room

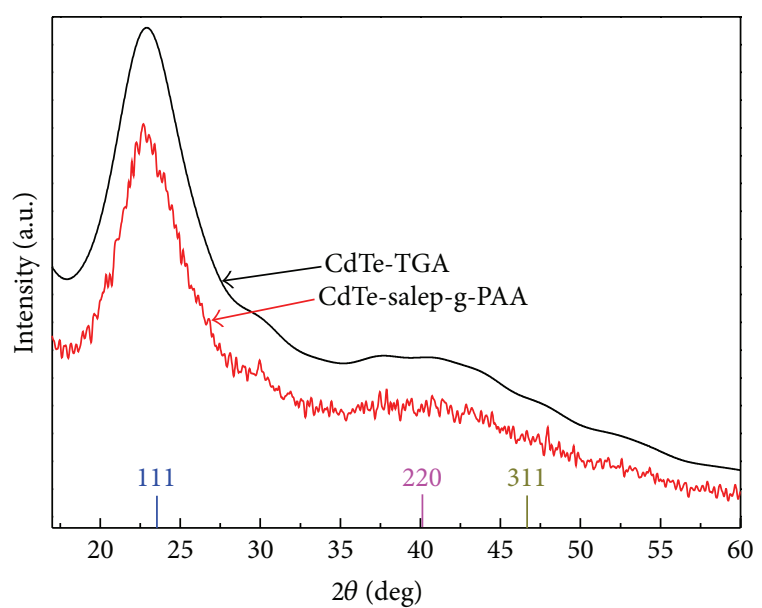

FIGURE 6: XRD patterns of CdTe-salep-g-PAA QDs.

temperature. The CdTe-salep-g-PAA QDs were characterized by various experimental techniques such as optical absorption, fluorescence and FT-IR, TG analysis, and TEM. The salep-g-PAA biopolymer changed significantly the fluorescence intensity of the CdTe QDs, which make them suitable for more biological applications.

\section{References}

[1] L. Lai, C. Lin, Z. Xu et al., "Spectroscopic studies on the interactions between CdTe quantum dots coated with different ligands and human serum albumin," Spectrochimica Acta Part A, vol. 97, pp. 366-376, 2012.

[2] J. Kang, X. Li, J. Geng et al., "Determination of hyperin in seed of Cuscuta chinensis Lam. by enhanced chemiluminescence of CdTe quantum dots on calcein $/ \mathrm{K}_{3} \mathrm{Fe}(\mathrm{CN})_{6}$ system," Food Chemistry, vol. 134, pp. 2383-2388, 2012.

[3] D. A. Tekdaş, M. Durmuş, H. Yanik, and V. Ahsen, "Photodynamic therapy potential of thiol-stabilized CdTe quantum dotgroup 3A phthalocyanine conjugates (QD-Pc)," Spectrochimica Acta Part A, vol. 93, pp. 313-320, 2012.

[4] T. Fang, X. Li, Q. Wang, Z. Zhang, P. Liu, and C. Zhang, "Toxicity evaluation of CdTe quantum dots with different size on Escherichia coli," Toxicology In Vitro, vol. 26, p. 1233, 2012.

[5] M. Chu, X. Pan, D. Zhang, Q. Wu, J. Peng, and W. Hai, "The therapeutic efficacy of CdTe and CdSe quantum dots for photothermal cancer therapy," Biomaterials, vol. 33, p. 7071, 2012.

[6] F. Qu and H. Li, "Selective molecular recognition of polycyclic aromatic hydrocarbons using CdTe quantum dots with cyclodextrin as supramolecular nano-sensitizers in water," Sensors and Actuators B, vol. 135, no. 2, pp. 499-505, 2009.

[7] S. Ge, J. Lu, L. Ge, M. Yan, and J. Yu, "Development of a novel deltamethrin sensor based on molecularly imprinted silica nanospheres embedded CdTe quantum dots," Spectrochimica Acta Part A, vol. 79, no. 5, pp. 1704-1709, 2011.

[8] Z. Yang and H.-T. Chang, "CdHgTe and CdTe quantum dot solar cells displaying an energy conversion efficiency exceeding 2\%," Solar Energy Materials and Solar Cells, vol. 94, no. 12, pp. 2046-2051, 2010. 
[9] L. Chen, Z. Qi, R. Chen, Y. Li, and S. Liu, "Sensitive detection of Epstein-Barr virus-derived latent membrane protein 1 based on CdTe quantum dots-capped silica nanoparticle labels," Clinica Chimica Acta, vol. 411, no. 23-24, pp. 1969-1975, 2010.

[10] J. Wang and H. Han, "Hydrothermal synthesis of high-quality type-II CdTe/CdSe quantum dots with near-infrared fluorescence," Journal of Colloid and Interface Science, vol. 351, no. 1, pp. 83-87, 2010.

[11] B. Xing, W.-W. Li, and K. Sun, "A novel synthesis of high quality CdTe quantum dots with good thermal stability," Materials Letters, vol. 62, no. 17-18, pp. 3178-3180, 2008.

[12] Y.-S. Li, F.-L. Jiang, Q. Xiao et al., "Enhanced photocatalytic activities of $\mathrm{TiO}_{2}$ nanocomposites doped with water-soluble mercapto-capped CdTe quantum dots," Applied Catalysis B, vol. 101, no. 1-2, pp. 118-129, 2010.

[13] J. Liu, Z. Shi, Y. Yu, R. Yang, and S. Zuo, "Water-soluble multicolored fluorescent CdTe quantum dots: synthesis and application for fingerprint developing," Journal of Colloid and Interface Science, vol. 342, no. 2, pp. 278-282, 2010.

[14] E. Lee, S. Gwon, Y. Son, and S. Kim, "Optical properties of photo- and thermo-responsive aqueous CdTe quantum dots/ spironaphthoxazine/poly(N-isopropylacrylamide) hybrid," Spectrochimica Acta Part A, vol. 97, pp. 806-810, 2012.

[15] T. Zhang, X. Sun, and B. Liu, "Synthesis of positively charged CdTe quantum dots and detection for uric acid," Spectrochimica Acta Part A, vol. 79, no. 5, pp. 1566-1572, 2011.

[16] M. A. Jhonsi and R. Renganathan, "Investigations on the photoinduced interaction of water soluble thioglycolic acid (TGA) capped CdTe quantum dots with certain porphyrins," Journal of Colloid and Interface Science, vol. 344, no. 2, pp. 596$602,2010$.

[17] Y.-F. Liu and J.-S. Yu, "Selective synthesis of CdTe and high luminescence CdTe/CdS quantum dots: the effect of ligands," Journal of Colloid and Interface Science, vol. 333, no. 2, pp. 690698, 2009.

[18] A. Sharma, C. M. Pandey, G. Sumana et al., "Chitosan encapsulated quantum dots platform for leukemia detection," Biosensors and Bioelectronics, vol. 38, no. 1, pp. 107-113, 2012.

[19] Y. Wang, H. Chen, C. Ye, and Y. Hu, "Synthesis and characterization of CdTe quantum dots embedded gelatin nanoparticles via a two-step desolvation method," Materials Letters, vol. 62, no. 19, pp. 3382-3384, 2008.

[20] N. Tomczak, D. Jańczewski, M. Han, and G. J. Vancso, "Designer polymer-quantum dot architectures," Progress in Polymer Science, vol. 34, no. 5, pp. 393-430, 2009.

[21] K. K. Tekinşen and A. Güner, "Chemical composition and physicochemical properties of tubera salep produced from some Orchidaceae species," Food Chemistry, vol. 121, no. 2, pp. 468-471, 2010.

[22] N. Georgiadis, C. Ritzoulis, E. Charchari, C. Koukiotis, C. Tsioptsias, and C. Vasiliadou, "Isolation, characterization and emulsion stabilizing properties of polysaccharides form orchid roots (salep)," Food Hydrocolloids, vol. 28, no. 1, pp. 68-74, 2012.

[23] A. Pourjavadi, M. e Doulabi, R. Soleyman, S. Sharif, and S. A. Eghtesadi, "Synthesis and characterization of a novel (salep phosphate)-based hydrogel as a carrier matrix for fertilizer release," Reactive and Functional Polymers, vol. 72, no. 10, pp. 667-672, 2012.

[24] D. K. Sinha and Y. N. Mohapatra, "Charge trapping and electroluminescence at quantum dots embedded in a polymer matrix," Organic Electronics, vol. 13, pp. 1456-1462, 2012.
[25] B. T. Raut, M. A. Chougule, S. Sen, R. C. Pawar, C. S. Lee, and V. B. Patil, "Novel method of fabrication of polyaniline-CdS nanocomposites: structural, morphological and optoelectronic properties," Ceramics International, vol. 38, no. 5, pp. 39994007, 2012.

[26] W. Trzeciakowski, "Effective-mass approximation in semiconductor heterostructures: one-dimensional analysis," Physical Review B, vol. 38, no. 17, pp. 12493-12507, 1988.

[27] G. Gordillo, J. M. Flórez, and L. C. Hernández, "Preparation and characterization of CdTe thin films deposited by CSS," Solar Energy Materials and Solar Cells, vol. 37, no. 3-4, pp. 273-281, 1995.

[28] Y. Masumoto and K. Sonobe, "Size-dependent energy levels of CdTe quantum dots," Physical Review B, vol. 56, no. 15, pp. 97349737, 1997. 

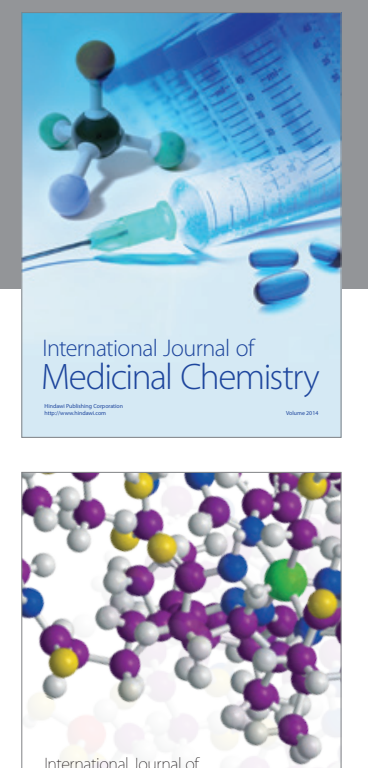

\section{Carbohydrate} Chemistry

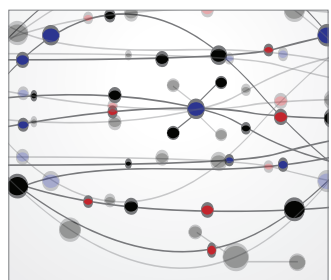

The Scientific World Journal
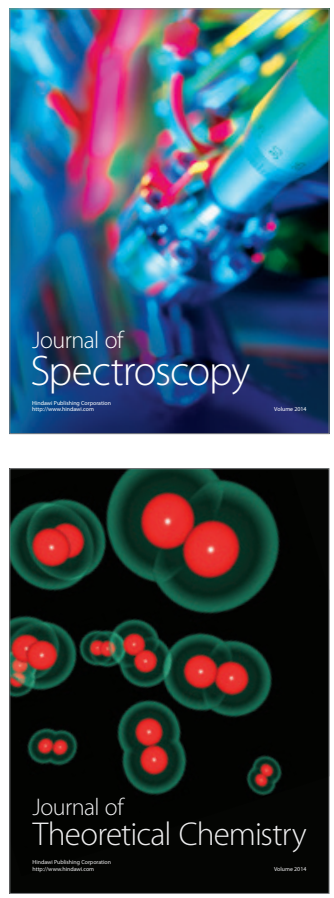
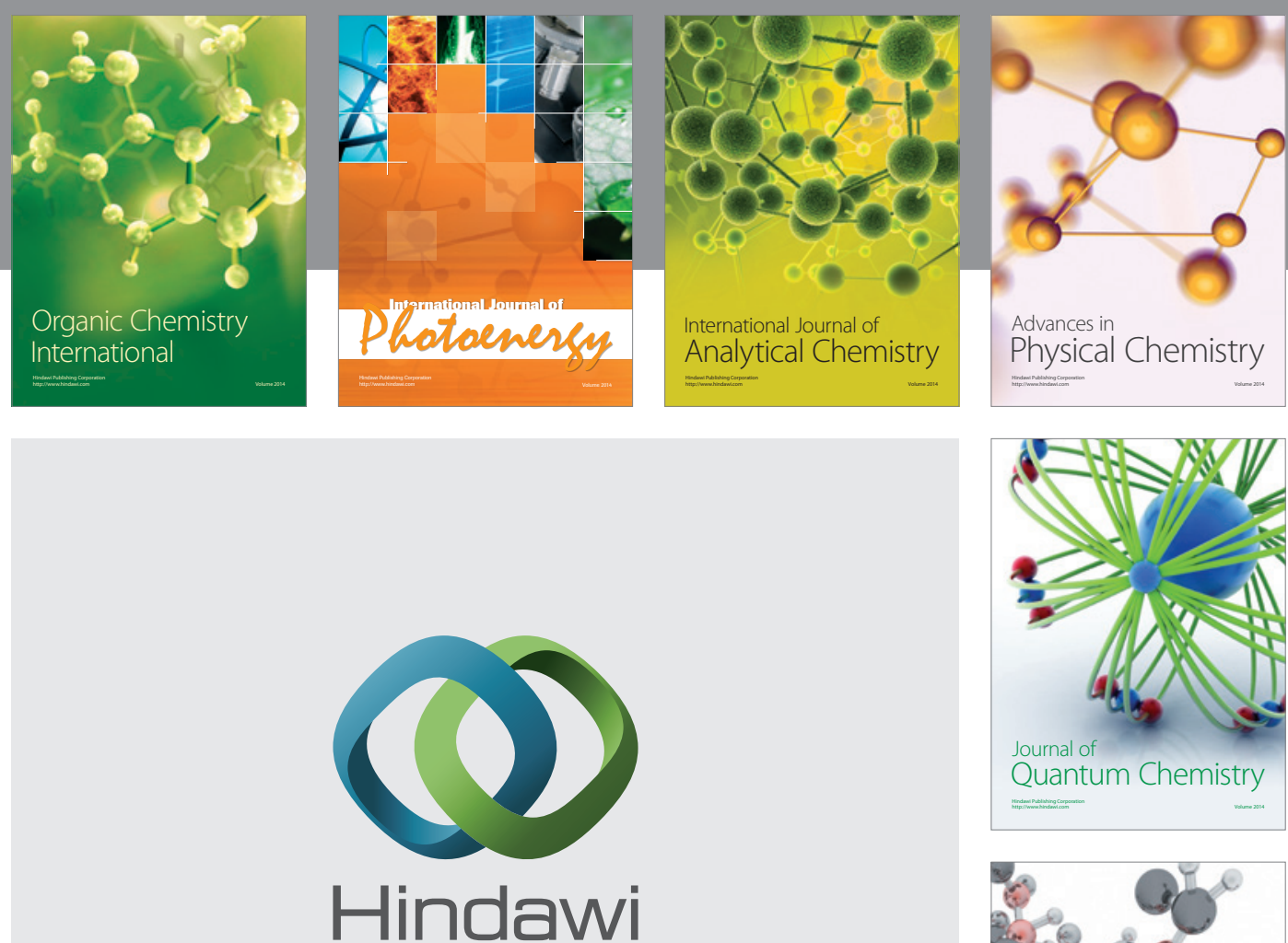

Submit your manuscripts at

http://www.hindawi.com

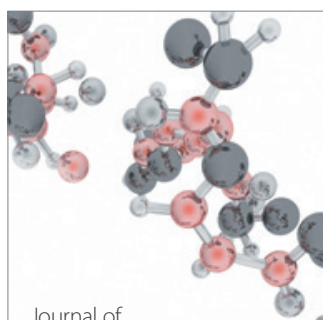

Analytical Methods

in Chemistry

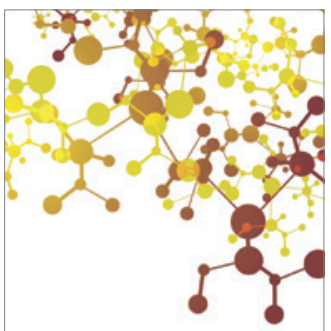

Journal of

Applied Chemistry

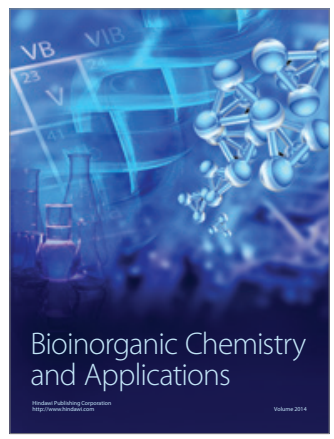

Inorganic Chemistry
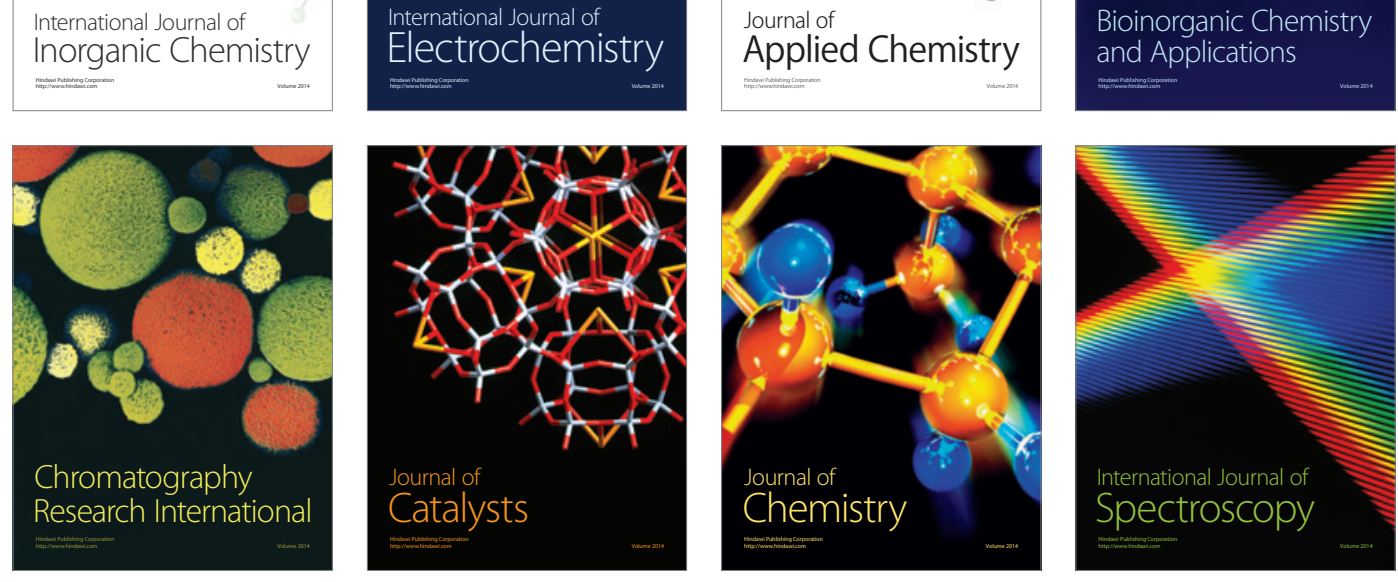